\title{
O trabalho sob a ótica das manipuladoras de alimentos de uma unidade hospitalar ${ }^{1}$
}

\author{
Work according to the viewpoint \\ of hospital food handlers
}

Cilce Helena Figueiredo Preza BERTIN²

Tania Beninga MORAIS ${ }^{3}$

Dirce Maria SIGULEM ${ }^{3}$

Magda Andrade REZENDE ${ }^{4}$

RESU M O

\section{Objetivo}

Analisar as percepções acerca da atividade profissional de um grupo de manipuladores de alimentos de um hospital público.

\section{Métodos}

A pesquisa, de cunho qualitativo, foi realizada em um serviço de nutrição e dietética de um hospital público de ensino da Cidade de São Paulo. Desenvolveu-se a partir de corpus obtido por técnica do grupo focal realizada com 15 funcionárias, sendo 8 vinculadas ao lactário e 7 à cozinha dietética. Os depoimentos foram gravados, transcritos e analisados sob o ponto de vista do conteúdo e das representações sociais. Posteriormente, a validação da análise foi realizada com as participantes. A caracterização socioeconômica foi realizada com uso de um formulário auto-aplicável.

\section{Resultados}

O trabalho é percebido como crucial para a sobrevivência, porém de grande responsabilidade social, além de implicar em rotina exaustiva. Além disso, constitui instância que possibilita apoio e relacionamento entre as trabalhadoras, embora não Ihes proporcione o status que julgam merecer. O trabalho é representado como instância simultânea de sofrimento e apoio; embora importante, tanto para elas mesmas, quanto para o grupo social. Ao mesmo tempo, chefias e os superiores se mostram alheios a todas as dificuldades.

\footnotetext{
1 Artigo elaborado a partir da tese de C.H.F.P. BERTIN, intitulada "Percepções sobre o trabalho de um grupo de manipuladores de alimentos em um serviço de nutrição e dietética". Universidade Federal de São Paulo; 2005. Apoio: Coordenação de Aperfeiçoamento de Pessoal de Nível Superior.

2 Universidade Federal de Mato Grosso, Faculdade de Nutrição, Departamento de Alimentos e Nutrição. Av. Fernando Corrêa da Costa, s/n., 78060-900, Cuiabá, MT, Brasil. Correspondência para/Correspondence to: C.H.F.P. BERTIN. E-mail: <bertin@terra.com.br>

3 Universidade Federal de São Paulo, Pós-Graduação em Nutrição. São Paulo, SP, Brasil.

${ }^{4}$ Universidade de São Paulo, Escola de Enfermagem, Departamento de Enfermagem Materno-infantil e Psiquiátrica. São Paulo, SP, Brasil.
} 
644 | C.H.F.P. BERTIN et al.

\section{Conclusão}

Por conseqüência, percebe-se que há necessidade de mudanças na organização do trabalho, a fim de reduzir os fatores que ocasionam cansaço, descontentamentos e desânimo nas manipuladoras. Faz-se necessário maior investimento, por parte da chefia do serviço, na adoção de estratégias gerenciais mais descentralizadas e participativas, respeitando, na medida do possível, as opiniões e diferenças individuais, bem como investindo em treinamentos periódicos dos trabalhadores.

Termos de indexação: Manipulação de alimentos. Pesquisa qualitativa. Responsabilidade social.

\section{A B S T R A C T}

\section{Objective}

The objective was to analyze how a group of food handlers from a public hospital perceive their professional activities.

\section{Methods}

This qualitative research was carried out in a nutrition and dietetic service of a public hospital school in the city of São Paulo. Its development was based on a corpus obtained by doing the focus group technique with 15 employees, of which 8 worked in the milk dispensary and 7 in the dietetic kitchen. The statements were recorded, transcribed and analyzed according to content and social representations. Later, the analysis was validated together with the participants. Socioeconomic status was determined with a self-assessment form.

\section{Results}

Labor is perceived as crucial for survival and of great social responsibility, in addition to being exhausting. Furthermore, work represents an instance that allows workers to support and relate to each other, although it does not provide the status they believe they deserve. Labor is simultaneously represented as an instance of suffering and support while it is important for themselves and for the whole social group. Meanwhile, supervisors and managers do not seem to notice their difficulties.

\section{Conclusion}

Consequently, the organization of the work needs changes in order to reduce factors that generate fatigue, unhappiness and discouragement among food handlers. Supervisors need to invest more in the implementation of decentralizing and more participative management strategies, respecting, whenever possible, the opinions and individual differences, as well as in the periodical training of the employees.

Indexing terms: Food handling. Qualitative research. Social responsibility.

\section{N T R O D U ÇÃ O}

De acordo com a Recomendação Internacional do Código de Práticas e Princípios Gerais de Higiene de Alimentos ${ }^{1}$, manipulador de alimentos é toda pessoa que manipula diretamente alimentos, quer processados ou não, bem como superfícies de contatos envolvidas com estes e/ou equipamentos e utensílios necessários para seu processamento. Destes profissionais se espera o cumprimento dos procedimentos adequados para higiene dos alimentos, de modo a assegurar ao consumidor alimento livre de contaminação.

Embora o arsenal tecnológico disponível para a produção de alimentos seja significativo, a qualidade das refeições ainda está diretamente relacionada ao desempenho da mão-de-obra², o que torna a manipulação um processo crítico. Os manipuladores de alimentos, em geral, são oriundos dos estratos socioeconômicos menos privilegiados, especialmente no Brasil. Além disso, a produção de refeições é caracterizada por tensão e premência de tempo, sendo comum a transformação da matéria-prima em produto, em cerca de quatro a seis horas ${ }^{3}$. Os serviços seguem rotinas padronizadas, rígidas e repletas de exigências a serem cumpridas, caracterizadas por movimentos repetitivos, levantamento de peso excessivo, permanência por períodos prolongados na postura em pé e modificação constante de procedi- 
mentos ${ }^{2}$. Acrescentam-se a esses fatores questões como o absenteísmo, a rotatividade e a polivalência, que afetam esses trabalhadores e que dificultam todo o processo produtivo contribuindo ainda com a insegurança alimentar, pois os manipuladores são recursos humanos importantes para a viabilidade da qualidade no preparo dos alimentos ${ }^{4}$.

Nesse contexto, é necessário levar em conta o elemento humano, tornando-se importante saber como o trabalhador percebe e age frente ao seu trabalho. Portanto, deve-se levar em conta as imagens dos seres humanos em relação ao trabalho, sua visão de futuro e seu conceito de autoridade, o que raramente acontece ${ }^{5}$. Assim, considerando que ainda são escassos os estudos relacionados à gestão de recursos humanos na área de nutrição e, principalmente, os que abordem trabalhadores do nível operacional e suas vivências em relação ao trabalho ${ }^{2,6}$, este estudo teve como objetivo analisar as percepções acerca da atividade profissional de um grupo de manipuladoras de alimentos de um hospital público na cidade de São Paulo.

\section{MÉ TO D O S}

Este estudo foi realizado a partir de uma abordagem qualitativa, de modo a permitir a apreensão da dinâmica das relações sociais, valorizando a vivência, a experiência e o cotidiano dos sujeitos ${ }^{7}$. O micro-cosmos, cenário deste estudo, foi um grande hospital de ensino da cidade de São Paulo, gerido de modo semelhante a seus congêneres.

A população do estudo foi constituída por cozinheiras, copeiras e lactaristas lotadas nos setores do lactário e da cozinha dietética do Serviço de Nutrição e Dietética (SND), totalizando 15 funcionárias. Estes setores foram escolhidos por serem críticos, pois fazem uso de rigorosas técnicas de assepsia para assegurar menor risco de contaminação possível, uma vez que têm como meta a inocuidade do produto final, tendo em vista o fato de seus clientes, crianças e pacientes necessitarem de dietas especiais. As manipuladoras que aceitaram colaborar com o estudo assinaram o Termo de Consentimento Livre e Esclarecido e o estudo foi autorizado pela diretoria do hospital e chefia do SND.

Utilizou-se entrevista coletiva conduzida sob a técnica de grupo focal, sendo esta um recurso que se vale de sessões ou entrevistas grupais semi-estruturadas. Tais fóruns são facilitadores da expressão, uma vez que a coordenação é realizada por técnico treinado no uso da compreensão da experiência e também, porque os participantes tendem a se apoiar mutuamente em sua expressão, o que não significa que somente concordem entre si, já que há também momentos de vivo debate $^{8-10}$. Dessa forma, as manipuladoras falaram livremente acerca do significado do trabalho e de si mesmas.

As 15 participantes foram divididas em dois grupos, chamados de A e B. Foi usado roteiro para conduzir a entrevista, buscando captar preferências, desagrados e valores do tema proposto, privilegiando também questões levantadas pelas participantes. Foram realizadas duas sessões de 90 minutos com cada um dos grupos. Os depoimentos foram gravados com autorização prévia das participantes. Abordaram-se aspectos gerais do trabalho, o significado, a rotina, as facilidades e as dificuldades encontradas. Estes pontos foram listados a partir da experiência do pesquisador, de revisão bibliográfica e da realização de entrevistas-piloto com grupo semelhante ao que participou do estudo. Antes das sessões de grupo focal, e com a finalidade de conhecer o cotidiano dos sujeitos, acompanhou-se o fluxo de trabalho com observação direta de suas atividades diárias.

Os depoimentos das manipuladoras foram transcritos na íntegra e analisados utilizando-se análise temática de conteúdo ${ }^{10}$, descobrindo-se os núcleos de sentido que compõem a comunicação e cuja presença ou freqüência de aparição pode significar algo para o objetivo analítico escolhido, e situando-se nos respectivos contextos o que foi dito pelas participantes. Foram construídas as categorias conceituais que permitiram 
passar dos elementos descritivos à interpretação. O projeto foi aprovado pelo Comitê de Ética em Pesquisa da Universidade Federal de São Paulo (Unifesp).

\section{RESULTADOSE DISCUSSÃO}

As 15 participantes do estudo eram mulheres na idade de 35 a 58 anos (média 48). Duas tinham menos do que 40 anos, cinco eram casadas, quatro divorciadas ou separadas, três solteiras e três viúvas. Sete nasceram no estado de São Paulo, sendo duas na capital e cinco no interior. Três eram da Bahia, duas de Minas Gerais, uma do Pará, uma da Paraíba e uma do Paraná. Três tinham primeiro grau incompleto, seis o primeiro grau completo, três o segundo grau incompleto e três o segundo grau completo.

Todas as trabalhadoras usavam transporte público para trabalhar, sendo que oito usavam ônibus e metrô e sete ônibus. O percurso entre a residência e o trabalho era realizado entre 30 a 90 minutos para ir, e entre 30 e 110 minutos para retornar. Todas, exceto uma, trabalhavam durante o dia, em jornada de 12 horas diárias alternadas com 36 horas de folga.

Quanto ao vínculo de trabalho, 11 participantes eram estatutárias, duas celetistas e duas tinham dois vínculos empregatícios, sendo que estas últimas trabalhavam em dois setores distintos do SND. O salário variava de 1,7 a quatro salários-mínimos, sendo que esta variabilidade se devia ao vínculo empregatício, ao cargo, ao tempo de serviço e a alguns benefícios incorporados ao salário. Duas não responderam a esta questão.

O tempo de trabalho na instituição das entrevistadas variava de 8 a 20 anos, sendo que a maioria tinha estabilidade no emprego. Quanto ao tempo de trabalho na função, oito das participantes era de 15 a 20 anos, cinco de três a oito anos e somente uma tinha menos de um ano.

Quanto ao local de serviço, sete trabalhavam no lactário, seis na cozinha dietética, uma na cozinha dietética e na copa, e uma no lactário e na cozinha geral. Das sete funcionárias da cozinha dietética, cinco desempenhavam a função de cozinheiras e duas eram responsáveis pela distribuição das dietas, sendo que uma delas também preparava as saladas. Das oito funcionárias do lactário, duas eram responsáveis pelo preparo das fórmulas lácteas e sopas, cinco pela distribuição e higienização de mamadeiras e uma pela esterilização e pelo envase de mamadeiras.

O trabalho é visto pelas manipuladoras sob os seguintes aspectos: (1) Importante para a sobrevivência, (2) Implica em rotina exaustiva, (3) Implica em grande responsabilidade, (4) Local de apoio e relacionamento, e (5) Manipuladores de alimentos não têm o status que julgam merecer.

\section{Importante para a sobrevivência}

Todas as manipuladoras trabalhavam por necessidade de sobrevivência. Algumas disseram que, se pudessem, não trabalhariam nesta profissão. Mesmo assim, com o passar do tempo acabaram por estabelecer fortes vínculos afetivos entre si, o que ameniza esta situação de constrição. Entretanto, o mundo é mediado pelo trabaIho, assim, o não-trabalho tira total ou parcialmente do indivíduo a sua identidade ${ }^{11}$. Paradoxalmente o trabalho é vinculado à escravidão, a "estar preso". Esta visão encontra-se ancorada na idéia de que só tem valor na sociedade quem tem trabalho, quem não o tem é considerado vagabundo, preguiçoso, pois o trabalho "dignifica o ser humano", o faz integrante da sociedade.

A relação do ser humano com o trabalho pode ser mais complexa e até conflitante. Este, apesar de pesado e indesejável, dá sentido à vida, eleva status, define identidade pessoal e impulsiona o crescimento individual. É indesejável, pela fragmentação, por ser burocrático e cheio de normas e exigências, mas é importante, principalmente, devido à necessidade de sobrevivência e de condicionamento social ${ }^{12}$.

Em concordância com um dos axiomas que norteiam a civilização ocidental: é necessário 
trabalhar para viver ${ }^{13}$. Algumas manipuladoras praticamente sustentam sozinhas suas casas, devido à ausência ou ao desemprego do cônjuge, havendo também, agravantes, como filhos e outros parentes sob sua responsabilidade. Vale ressaltar que, o censo demográfico do Instituto Brasileiro de Geografia e Estatística (IBGE) revela que, no ano 2000, na Região Sudeste o percentual de mulheres responsáveis pelo domicílio era elevado $(25,6 \%)^{14}$.

Evidencia-se que as participantes deste estudo praticamente não abandonam o emprego, fato demonstrado pelo longo tempo de trabalho na instituição. Neste sentido, é significativa a conjuntura econômica e social do País, marcada pela situação de desemprego. O ano de 2003 encerrou-se com um quadro crítico de 10 milhões de desempregados ${ }^{14}$, isto é, $12,8 \%$ da população economicamente ativa. Esta cifra chegou a 14,6\% na Região Metropolitana de São Paulo em março do mesmo ano, ou seja, 1,33 milhões de pessoas. Assim, o trabalho é valorizado por sua escassez. O emprego é uma oportunidade que não pode ser desperdiçada.

Conseqüentemente, o mercado de trabalho dita as normas para a sociedade. Quem não está preparado adequadamente não tem lugar nesse mercado, e as manipuladoras demonstraram saber disto. Ingressaram no emprego atual mesmo com poucos anos de escolaridade e ressaltaram que, atualmente, não conseguiriam outra oportunidade devido à acirrada competitividade. Além disso, mencionaram o fantasma da idade avançada, isto é, avançada em termos de quesito de competição no mercado. Vê-se a imagem da velhice enraizada na cultura ocidental como um estorvo e improdutividade, aspecto que ancora a idéia de juventude, como sinônimo de dinamismo, saúde, força e disposição para o trabalho.

Essas percepções partilhadas pelas manipuladoras de alimentos constituem modos de conceber esta fase da vida com os significados e os valores da cultura na qual se inserem. Nota-se que o Brasil ainda valoriza pouco seus idosos e enfatiza a velhice como condição desfavorável, muitas vezes, indesejável ${ }^{15}$. A crise do desemprego agrava este problema, pois a tendência é preterir os mais velhos em função dos mais jovens ${ }^{16}$.

Interessante observar, também, em alguns depoimentos, a mediação do divino para garantir trabalho e salário. A crença é uma das formas de superação e enfrentamento, e as faz gratas pelo emprego. Assim, sujeitam-se até mesmo a trabaIhar em condições que consideram não satisfatórias.

Algumas das entrevistadas se sentiam mais tranqüilas por terem adquirido estabilidade no emprego, possibilidade que existe em instituição pública. Percebem-se como tendo uma grande vantagem por estarem empregadas, especialmente na conjuntura nacional tão difícil. No entanto, observam que a estabilidade pode também diminuir o compromisso de algumas colegas com o trabalho, acarretando dificuldade para aquelas que são responsáveis, e elas todas se percebem responsáveis.

Outro ponto levantado pelas trabalhadoras diz respeito aos atrasos no pagamento de horas extras, ocasionando constrangimentos e humilhações. Notou-se uma repetição insistente do tema em momentos diferentes, recorrência indicativa de sua importância, revelando o investimento psicológico das manipuladoras com a questão ${ }^{10}$. Percebem a situação como descaso da administração, uma vez que esta não as procura, quer com soluções, quer com explicações para os atrasos sucessivos.

\section{Implica em rotina exaustiva}

Todas as participantes alegaram cansaço. Algumas se sentiam cansadas fisicamente, enquanto outras diziam que se cansavam devido às cobranças, à desvalorização de seu trabalho e à tensão em que se vêem envolvidas. O mesmo foi detectado em pesquisa realizada em Unidade de Alimentação e Nutrição Hospitalar de Florianópolis, no ano de 2002. Segundo esta pesquisa, $53,8 \%$ dos trabalhadores do SND entrevistados 
achavam seu trabalho cansativo e 73,1\% sentiam-se cansados no final do dia. Segundo a autora, isto se deve a múltiplos fatores, como: jornada diária de mais de 8 horas, esforço físico, ruídos excessivos, temperatura ambiente elevada, falta de materiais, além do acúmulo de jornadas de trabalho, necessário para a cobertura de folgas e férias, o que agrava ainda mais a situação ${ }^{17}$.

Algumas manipuladoras enfatizaram a necessidade do trabalho em equipe e o quanto se sentem desmotivadas, exatamente porque isso não acontece. As chefias se mantêm distantes destas situações, como se não existissem, o que as deixa desapontadas. Procuram, na medida do possível, escolher plantões junto aos funcionários que sabem ser responsáveis. Além disso, percebem o trabalho como troca de favores entre colegas. Fazem algo por alguém para, quando precisarem, contar com auxílio, como uma caixa de compensações. Esta assume também um caráter metafísico, neste caso, o crédito obtido por ter realizado um favor é creditado a Deus.

Outro aspecto evidenciado diz respeito à falta de um bom relacionamento com a chefia e com alguns colegas. Esses foram os motivos destacados para que o trabalho seja negativamente representado pelas manipuladoras de alimentos. Sabe-se que o relacionamento interpessoal com superiores e colegas, bem como o clima e a estrutura da organização, são agentes potencialmente negativos e estressores ${ }^{18}$. Atitudes simples, como um cumprimento ou uma felicitação, são consideradas importantes por elas e fazem com que se sintam valorizadas, principalmente pela chefia.

Nos depoimentos prestados pelas manipuladoras, as chefias são apresentadas como intocáveis e distantes. Atos que, vindo dos subordinados seriam passíveis de repreensão, são permitidos às chefias. Assim, se cristaliza a representação de chefia como intocável, estando acima do bem e do mal, e que nunca pode ser questionada ou contrariada.

Ainda que as trabalhadoras vivenciem situações complicadas no trabalho, atribuem-lhe grande importância, tanto para a sobrevivência, como para o amadurecimento individual (referindo-se à maior responsabilidade que adquirem). No entanto, existem momentos no dia-a-dia em que entram em verdadeiro conflito, quando uma situação de dificuldade traz mais desgosto e desânimo do que realização e prazer, sendo o trabalho, ao mesmo tempo, motivo de satisfação e de sofrimento.

\section{Implica em grande responsabilidade}

Garcia $^{19}$, em seu estudo, evidenciou que a contaminação e a preparação das dietas especiais, as quais exigem procedimentos diferenciados, são os aspectos técnicos com os quais os funcionários da cozinha mais se preocupam. Neste estudo, o fato de as manipuladoras serem responsabilizadas ou até penalizadas por qualquer erro que venha a atingir a produção dos alimentos faz com que a noção de responsabilidade se torne onipresente no cotidiano dessas trabalhadoras. Assim, trabaIham com ansiedade, e, eventualmente, até com sentimentos de impotência e medo. É evidente que o trabalho em Unidade de Alimentação e Nutrição requer esforço físico, e elevado grau de atenção, em virtude da complexidade do serviço e das exigências de padrões de qualidade higiênico-sanitários e de atendimento ${ }^{20}$.

As manipuladoras, conscientes da importância de tratar bem o paciente, demonstraram se sentir responsáveis pelo mesmo. Percebe-se que estão envolvidas emocionalmente com as atividades, o que pode ser interpretado como um mecanismo psicológico de defesa. Neste caso, a atividade tem como função tornar possível a permanência do trabalhador em uma realidade permeada pela pressão e pela rigidez. Tal mecanismo atua na preservação dos equilíbrios físico e psíquico do indivíduo ${ }^{18}$. No entanto, as manipuladoras sabem que, em alguns momentos, o trabalho delas não é bem recebido, não sendo valorizado como gostariam. Sentem-se, inclusive, usadas, o que, evidentemente, as desaponta sobremaneira. 
Outro aspecto diz respeito ao que interpretam como falta de compromisso de alguns colegas em relação ao trabalho. Não é incomum precisarem fazer tarefas que competem aos outros ou refazer tarefas que não foram adequadamente executadas. Atribuem esta situação à personalidade, à educação recebida, ou, até mesmo, ao fato de alguns não gostarem do que fazem. Sabe-se que o sucesso da interação entre colegas parece intimamente ligado a dois aspectos interdependentes: a característica de personalidade de cada um e a percepção social que cada um utiliza para conhecer o outro. Como as personalidades não são idênticas, as percepções serão diferentes, causando distorções das reais características pessoais daquele com quem se está pretendendo interagir ${ }^{21}$.

\section{Local de apoio e relacionamento}

Todas as manipuladoras relataram gostar de seu trabalho, manifestando o desejo de permanecerem nele, apesar dos problemas, como: falta de equipamentos e material de consumo, área física - ambiência e instalações deficientes, gêneros alimentícios de baixa qualidade e fornecidos em quantidades insuficientes, relacionamentos conflituosos com superiores hierárquicos. Paradoxalmente, algumas se sentem absolutamente ligadas ao trabalho. Percebem que seu trabalho é importante para a recuperação do paciente, sua própria identidade é criada em função desta situação, e criam entre si uma rede de apoio emocional e social.

Sabe-se que os hospitais no mundo ocidental foram criados por instituições religiosas cristãs ${ }^{22}$, às quais estiveram ligados durante séculos. A idéia de altruísmo é algo comum na representação social do hospital pela sociedade brasileira, assim, a inserção em uma instituição hospitalar per si pode ser interpretada como missão, algo que tem um atrativo poderoso aos olhos da população em geral. Esta necessidade de atribuir este sentido ao trabalho e o considerar uma atividade de ajuda ao outro, é tão importante para o ser humano que já foi identificada em outras categorias profissionais ${ }^{23}$ que a priori parecem distantes, como, por exemplo, administradores.

Os depoimentos demonstraram a preocupação com o outro, de serem úteis aos pacientes, embora este componente de cuidar do outro sirva também para formar a identidade. O pertencimento a uma organização pública de saúde implica em algum tipo de identidade coletiva, dada pela característica de ser público e da saúde $^{24}$. Um dos elementos definidores dessa identidade consiste nas atividades voltadas para a produção de bens e serviços de promoção do bem-estar físico, mental e social dos usuários ${ }^{24}$. Portanto, o fazer pelo e para o outro, dá às manipuladoras uma dimensão de maior importância para o trabalho realizado.

Percebeu-se também, que havia, entre algumas das participantes, fortes relações de afeto, em função das quais trocam confidências e se apóiam. Este apoio acontece não somente pela relação, mas também porque passam a assumir tarefas conjuntas, dividindo as responsabilidades. Aliado a isso, algumas parecem não ter com quem compartilhar problemas e aflições no âmbito doméstico, tornando os laços afetivos mais evidentes e intensos. Percebe-se que o local de trabalho pode ser também um ambiente de apoio mútuo, o que não prejudica, a priori, o desenrolar das atividades.

Evidencia-se, portanto, que as representações sobre o trabalho não se limitam à necessidade, mas relacionam-se ao espaço cotidiano e de convivência. Há uma forte conotação de satisfação em decorrência da associação com alguns colegas e, eventualmente, com pacientes. O fato de estar em contato com os outros e de manter relações numerosas e, às vezes intensas, funciona como um estimulante para si mesmo. Esse aspecto pode vir a potencializar propostas de trabalho voltadas para o trabalho em equipe ${ }^{23}$. 
Manipuladores de alimentos não têm o status que julgam merecer

Os profissionais que atuam na área de alimentação são nutricionistas e funcionários operacionais ou manipuladores de alimentos, estes últimos comumente denominados auxiliares de nutrição. No caso dos sujeitos desta pesquisa, manipuladoras de alimentos, sentem-se desvalorizadas por não serem reconhecidas enquanto uma categoria diferente e, com certa freqüência, serem, segundo elas, confundidas com nutricionistas. Sabe-se que é comum a identificação de profissionais e auxiliares como sendo um só tipo de profissional. Assim, ainda que não se sintam desconfortáveis por serem vistas como nutricionistas, às quais é associado o poder de decisão, sentem-se mal por não serem reconhecidas pelo que são, de fato, e por seu importante papel de auxiliares não ter a visibilidade merecida.

Outras dificuldades em relação à desigualdade de papéis foram apontadas. Parece-Ihes que aos maiores níveis hierárquicos correspondem o poder e os privilégios. Estes, permitindo a seus detentores desempenhar as funções como lhes convém, inclusive, desrespeitando a ética profissional, segundo depoimentos. Não somente o desejo do trabalhador não é visualizado pelos que têm poder para decidir, como também é preciso fazê-lo calar, por medo que ele venha a incomodar. Elas se reconhecem como seres humanos, iguais aos outros, com desejos, anseios e vontades e que se sentem incomodadas pelo seu cerceamento.

O exemplo do uniforme é paradigmático, tendo sido objeto de intensa discussão. As manipuladoras usam avental verde como uniforme, enquanto que, nos demais serviços do hospital, este é de cor branca. Este fato as faz sentir, a priori, à margem. Outra questão ressaltada foi a ausência de corte no avental, enquanto que as nutricionistas, suas superiores hierárquicas, usam uniformes modelados. Estes dois atributos, cor e forma, às colocam à margem e parecem negar suas identidades como mulheres, pela ausência de forma. Sentem-se menosprezadas por terem as chefias lhes escolhido algo dessa natureza. Conforme sua representação, o uniforme deveria ser branco, que traz conotação de limpeza e higiene. Assim, algumas manipuladoras do setor do lactário decidiram, por conta própria, adotar um uniforme semelhante ao da maioria dos profissionais graduados do hospital, tais como nutricionistas, enfermeiros, médicos, e outros: um avental branco com nome e monograma bordados. O próprio fato de terem adotado um uniforme sem ter havido reação por parte da chefia, que ignorou o fato, diz muito acerca do alheamento desta, e corrobora o que vinha sendo dito pelas manipuladoras.

No que diz respeito ao uniforme, é evidente o desejo de se valorizarem, tanto aos seus próprios olhos, quanto aos dos outros, o que, aliás, é normal. Lamentável é que a iniciativa de mudanças não tenha partido da chefia que, neste caso, teria se mostrado sensível às justas necessidades da equipe. A questão do uniforme, propriamente, pode ser analisada pelo conceito de persona de Jung ${ }^{25}$. Persona é a forma pela qual o ser humano se apresenta ao mundo e a partir qual se relaciona com os outros, incluindo os papéis sociais, o tipo de roupa que se escolhe para usar e o estilo de expressão pessoal, servindo para proteger o ego e a psique das diversas forças e atitudes sociais. À medida que se começa a agir de determinada maneira, a desempenhar um papel, o ego se altera gradualmente nessa direção ${ }^{25}$.

Vale ressaltar que, na área da saúde coexistem profissionais com formação diferente, cada um com normas, parâmetros, visões de mundo e noções de ética. Muitas vezes, percebe-se no ambiente de trabalho que a integração entre esses profissionais ocorre de forma desarmônica, e tal fato pode ter como uma das causas a falta de visão interdisciplinar de todos. Nas organizações hospitalares, alguns profissionais têm dificuldades de afirmação de um campo de autonomia, sendo a falta de relações igualitárias entre esses profissionais e os médicos a regra nessas organizações $^{20}$. Nessas instituições, o relacionamento 
interno corresponde, com freqüência, ao status das diferentes profissões na sociedade ${ }^{26}$, o que remete à noção de divisão cartesiana de trabalho, ainda presente nos sistemas contemporâneos de produção. Esta divisão, preconizada por Taylor, faz prevalecer o controle do trabalho por aqueles que o administram, ou seja, reforça-se a divisão do trabalho em função da inserção social.

No que diz respeito aos usuários, isto é, os pacientes, há um bom relacionamento, segundo as entrevistadas. Elas não se sentem desrespeitadas por estes, embora sintam que seu trabalho não é reconhecido, tal como no estudo de Maciel ${ }^{17}$, no qual funcionários expressam seu desapontamento porque muitos pacientes, e até pessoas do seu convívio social, ignoram as funções exercidas pelos trabalhadores do SND de um hospital. Mesmo assim, acham importante oferecer aos pacientes credibilidade e confiança.

\section{O N CLUSÃ O}

As manipuladoras de alimentos têm uma representação de trabalho fortemente permeada por ambivalência. Este ora Ihes desencadeia ojeriza, ora afeto. Mesmo assim, prevalece uma concepção positiva, pois o trabalho Ihes acrescenta em termos de identidade e permite o estabelecimento de vínculos afetivos e de amparo mútuo com alguns colegas. Com as chefias a relação varia da indiferença ao mal-estar, não havendo por parte desta o apoio que esperavam para o enfrentamento dos problemas estruturais e relacionais. Assim, o ambiente e o relacionamento interpessoal têm um peso fundamental nas relações com o mundo do trabalho.

Destacam-se a avaliação que fizeram acerca da atividade, bem como as propostas de superação das dificuldades, que foram corroboradas nas visitas que tinham sido realizadas nos setores estudados antes da realização das sessões de grupo focal. As propostas elencadas pelas manipuladoras são conseqüências lógicas dos problemas levantados.
As principais propostas dizem respeito à necessidade de mudar o próprio paradigma do trabalho, no qual o aspecto de humanização nos serviços de saúde deve ser considerado agregando as auxiliares aos fóruns decisórios. A responsabilização, por meio da decisão compartilhada, leva à superação do modelo taylorista de administração. Como elas mesmas percebem, há necessidade de mudanças dos fluxos, entre outros pontos, e as mudanças poderiam acontecer de modo mais efetivo.

É necessário que se analisem os manipuladores de alimentos além do plano profissional, enfocando-os como uma categoria socialmente construída. Para um maior crescimento e desempenho dos Serviços de Nutrição e Dietética, é necessário que se reconheça o valor dos seus trabalhadores, pois estes são portadores de um rico conhecimento adquirido, e que deve ser considerado e entendido em seu contexto. De qualquer modo as mudanças não serão imediatas, mas haverá grande probabilidade de que o trabalho nos SND tome um novo rumo, no qual as pessoas possam contribuir de modo mais participativo.

\section{OLABORADORES}

C.H.F.P. BERTIN e M.A. REZENDE participaram do planejamento e da execução da pesquisa, da análise dos dados e da redação do manuscrito. D.M. SIGULEM e T.B. MORAIS participaram do planejamento da pesquisa e da análise dos dados.

\section{REFERÊ NCIAS}

1. Food and Agriculture Organization. Codex Alimentarius. Recommended international code of practice-general principles of food hygiene. CAC/RCP 1-1969, Rev. 4-2003. Roma: FAO; 2003.

2. Matos $\mathrm{CH}$, Proença RPC. Condições de trabalho e estado nutricional de operadores do setor de alimentação coletiva: um estudo de caso. Rev Nutr. 2003; 16(4):493-502. doi: 10.1590/S1415-5273 2003000400012. 
3. Lanzillotti HS. Gerência de recursos humanos em alimentação institucional. Rev Nutr. 1994; 7(2): 89-112.

4. Cavalli SB, Salay E. Gestão de pessoas em unidades produtoras de refeições comerciais e a segurança alimentar. Rev Nutr. 2007; 20(6):657-67. doi: 10.1590/S1415-52732007000600008.

5. Bom Sucesso EP. Relações interpessoais e qualidade de vida no trabalho. Rio de Janeiro: Qualitymark; 2002.

6. Bosi MLM. Trabalho e subjetividade: cargas e sofrimento na prática da nutrição social. Rev Nutr. 2000; 13 (2):107-15. doi: 10.1590/S1415-5273 2000000200005.

7. Minayo MCS, organizador. Pesquisa social: teoria, método e criatividade. 18a. ed. Petrópolis: Vozes; 2001.

8. Correia AC. Um instante de reflexão sobre o homem e o trabalho. Cad Pesq Adm. 2000; 1(11):12-7.

9. Rodrigues MVC. Qualidade de vida no trabalho. 9a. ed. Petrópolis: Vozes; 2002.

10. Bardin L. Análise de conteúdo. Lisboa: Edições 70; 1994.

11. Abusabha R, Woelfel ML. Qualitative vs quantitative methods: two opposites that make a perfect match. J Am Diet Assoc. 2003; 103(5): 566-9.

12. Kosny A. Joint stories and layered tales: support, contradiction and meaning construction in focus group research. The Qualitative Report [e-journal]. 2003 [cited 2004 Aug 18]; 8(4):539-48. Available from: <http://www.nova.edu/ssss/QR/QR8-4/ kosny.pdf $>$.

13. Aranha MLA, Martins MHP. Filosofando: introdução à filosofia. 3a. ed. São Paulo: Moderna; 2003.

14. Instituto Brasileiro de Geografia e Estatística Pesquisa de orçamentos familiares 2002-2003: primeiros resultados. [acesso 2004 nov 5]. Disponível em <http://www.ibge.gov.br>.

15. Lima MA. A gestão da experiência de envelhecer em um programa para a terceira idade [documento online]. UNATI/UERJ; 2004 [acesso 2004 nov14]. Disponível em: <http://www.intelecto.net/ cidadania>
16. Portella MR, Bettinelli LA. Humanização da velhice: reflexões acerca do envelhecimento e o sentido da vida. O Mundo da Saúde. 2003; 27(3):465-72.

17. Maciel TRS. Fatores interferentes na satisfação dos trabalhadores de uma Unidade de Alimentação e Nutrição Hospitalar [dissertação online]. Florianópolis: Universidade Federal de Santa Catarina; 2002 [acesso 2004 jun 25]. Disponível em: <http:// www.ibict.br/bdtd>.

18. Ladeira MB. O processo do stress ocupacional e a psicopatologia do trabalho. Rev Adm. 1996; 31(1): 64-74.

19. Garcia RWD. A dieta hospitalar na perspectiva dos sujeitos envolvidos em sua produção e em seu planejamento. Rev Nutr. 2006; 19(2):129-44. doi: 10.1590/S1415-52732006000200001.

20. Santana AMC. A produtividade em unidades de alimentação e nutrição: aplicabilidade de um sistema de medida e melhoria da produtividade integrando a ergonomia [tese]. Florianópolis: Universidade Federal de Santa Catarina; 2002.

21. Bergamini CW. Psicologia aplicada à administração de empresas: psicologia do comportamento organizacional. 4a. ed. São Paulo: Atlas; 2005.

22. Galvão CR, Federighi WJP. O hospital e o administrador hospitalar: um breve resgate histórico. O Mundo da Saúde 2002; 26(2):209.

23. Morin EM. Os sentidos do trabalho. Rev Adm Empres. 2001; 41(3):8-19.

24. Vaitsman J. Cultura de organizações públicas de saúde: notas sobre a construção de um objeto. Cad Saúde Pública. 2000; 16(3):847-50.

25. Fadiman J, Frager R. Teorias da personalidade. São Paulo: HARBRA; 2002.

26. Tajra SF, Santos SA. Tecnologias organizacionais na saúde: um enfoque prático das principais ferramentas de organização e de qualidade para as empresas na área de saúde. São Paulo: Látria; 2003.

Recebido em: 23/10/2007

Versão final reapresentada em: 23/10/2008 Aprovado em:18/11/2008 